\title{
Coupled thermo-hydro-mechanical modelling of carbon dioxide sequestration in saline aquifers considering phase change
}

\author{
Weiyong $\mathrm{Lu}^{1, *}$ and Xin Zhang ${ }^{2}$ \\ ${ }^{1}$ School of Mines, Luliang University, Lvliang, Shanxi 033000, China \\ ${ }^{2}$ School of Minerals and Energy Resources Engineering, Faculty of Engineering, University of New South Wales, Sydney NSW 2052, Australia
}

Carbon dioxide $\left(\mathrm{CO}_{2}\right)$ sequestration in saline aquifers is considered to be one of the most viable measures to control its emissions. During the process of $\mathrm{CO}_{2}$ injection, phase changes of gas, liquid and supercritical $\mathrm{CO}_{2}$ will lead to changes in the density, dynamic viscosity, specific heat capacity and $\mathrm{CO}_{2}$ heat conductivity and solubility in water, which will influence the injection pressure and spatial distribution of $\mathrm{CO}_{2}$. To study the characteristics of injection pressure and spatial distribution of $\mathrm{CO}_{2}$ in saline aquifers, equations of state such as Peng-Robinson equation were used to realize the continuous calculation of the physical property parameters of gas, liquid and supercritical $\mathrm{CO}_{2}$. Based on the continuous physical property parameters, a fully thermo-hydro-mechanical (THM) coupled model was developed and then solved and verified using COMSOL Multiphysics software. It has been shown in this study that: (i) the predicted $\mathrm{CO}_{2}$ injection pressure by the THM coupled model is higher than that obtained from the uncoupled model; (ii) at the top boundary of the reservoir, the spatial distribution of $\mathrm{CO}_{2}$ can be divided into a rapid increase region, a slow decrease region, a rapid decrease region and an initial saturation region along the direction of $\mathrm{CO}_{2}$ migration and (iii) larger the reservoir geothermal gradient, more obvious is the gravity override effect.

Keywords: Carbon dioxide sequestration, phase change, saline acquifers, thermo-hydro-mechanical modelling.

CARBON DIOXIDE $\left(\mathrm{CO}_{2}\right)$ is considered to be one of the main greenhouse gases (GHGs) that results in global warming of the earth's atmosphere ${ }^{1,2}$. Methods to effectively dispose of man-made $\mathrm{CO}_{2}$ is important now. $\mathrm{CO}_{2}$ capture and storage (CCS) is one of the most effective methods to reduce massive $\mathrm{CO}_{2}$ emissions into the atmosphere ${ }^{3,4}$. At present, deep saline aquifers, depleted oil, gas and coal reservoirs and salt caverns are considered to be the major geological sequestration media for the next $10-100$ years. Deep saline aquifers with large

\footnotetext{
*For correspondence. (e-mail: 489698551@qq.com)
}

storage capacity and global scope are widely distributed. It is estimated that nearly 600 billion tonnes of $\mathrm{CO}_{2}$, which is equivalent to the total man-made $\mathrm{CO}_{2}$ production in the next 20 years, can be stored in saline aquifers of the Utsira sandstone reservoirs of the Sleipner field in Norway $^{5,6}$.

At present, 15 large commercial CCS projects are being conducted in the Salah of Algeria, the Snøhvit and Sleipner gas fields of Norway, and the Quest project in Canada $^{7}$. According to the research statistics, seven billion tonnes of $\mathrm{CO}_{2}$ worldwide, needs to be disposed of yearly by geologic sequestration to effectively control man-made $\mathrm{CO}_{2}$ emissions ${ }^{5}$. A series of physical and chemical changes will occur with massive $\mathrm{CO}_{2}$ injection into saline aquifers, including multiphase fluid flow, change in effective stresses in the saline aquifers, dissolution of $\mathrm{CO}_{2}$ in brine and chemical reactions in brine, reservoir rock minerals and $\mathrm{CO}_{2}$.

$\mathrm{CO}_{2}$ sequestration in deep saline aquifers is a complex, mutually coupled process of seepage fields, stress fields and temperature fields. To describe this complex process, a series of mathematical models have been developed and are gradually being modified. The developed and modification of models has led to the development process from considering a single seepage field to hydro-mechanical coupled fields and then to thermo-hydro-mechanical (THM) coupled fields ${ }^{3,7-12}$. Numerical simulation is considered as the most suitable method to study the complex relation among different fields during $\mathrm{CO}_{2}$ sequestration. By solving the coupled equations of numerical simulation, the mechanism of $\mathrm{CO}_{2}$ sequestration can be better understood. Moreover, $\mathrm{CO}_{2}$ storage locations can be properly selected by accurate calculation of storage capacity, and the $\mathrm{CO}_{2}$ injection pressure and its spatial distribution in the aquifers can be effectively predicted. $\mathrm{CO}_{2}$ injection pressures can also be controlled to prevent cap rock fracture, which would lead to sequestrated $\mathrm{CO}_{2}$ leaking into the atmosphere ${ }^{13-17}$.

The THM coupled model used in this study consists of the mechanical equilibrium equation, mass continuity equation and equation of energy conservation. The physical parameters of $\mathrm{CO}_{2}$ density, dynamic viscosity, specific 


\section{RESEARCH ARTICLES}

heat capacity, thermal conductivity coefficient and solubility of $\mathrm{CO}_{2}$ in water are used in these three equations. The physical parameters of $\mathrm{CO}_{2}$ will change with changes in environmental temperature and pressure.

Under standard conditions, $\mathrm{CO}_{2}$ can be considered an ideal gas with a density of $1.872 \mathrm{~kg} / \mathrm{m}^{3}$. The pressure and temperature in saline aquifers are usually higher than the critical temperature $(304.25 \mathrm{~K})$ and critical pressure (7.39 $\mathrm{MPa}$ ) of $\mathrm{CO}_{2}$. Under such conditions, the density of $\mathrm{CO}_{2}$ is similar to that of a liquid, whereas its dynamic viscosity is close to that of a gas. This $\mathrm{CO}_{2}$ state is called the supercritical state. During injection of $\mathrm{CO}_{2}$ from the ground into deep saline aquifers, the $\mathrm{CO}_{2}$ phase will change from gas to liquid and then to the supercritical state. Therefore, it is impractical to consider $\mathrm{CO}_{2}$ density as a constant. Moreover, the ideal equation of state (EoS) of a gas can be used to calculate the density of $\mathrm{CO}_{2}$ in the gaseous state. To calculate density of $\mathrm{CO}_{2}$ in its different states (gas, liquid and supercritical according to one formula), the Peng-Robinson state equation, and the Span and Wagner state equation have been developed ${ }^{7,18}$.

Although coupled models of the geologic sequestration process have been continuously improved, currently some disadvantages remain in the models used. Using the Peng-Robinson state equation, and the Span and Wagner state equation, the fully coupled model can be used to calculate the density of $\mathrm{CO}_{2}$ in different states. However, other physical parameters, such as dynamic viscosity, specific heat capacity, thermal conductivity coefficient and solubility of $\mathrm{CO}_{2}$ in water cannot be calculated.

To study the effects of changing physical parameters on the $\mathrm{CO}_{2}$ injection process, we first studied the calculation models for $\mathrm{CO}_{2}$ density, dynamic viscosity, specific heat capacity, thermal conductivity coefficient and $\mathrm{CO}_{2}$ solubility in brine. The physical parameters of $\mathrm{CO}_{2}$ in different states were then calculated using the calculation models. Then, we established a THM coupled model for $\mathrm{CO}_{2}$ in gas, liquid and supercritical states. Based on the THM coupled model, the injection pressure and spatial distribution of $\mathrm{CO}_{2}$ under the coupled THM effect were then determined.

\section{Thermodynamic properties of $\mathrm{CO}_{2}$}

\section{Calculation model for density of $\mathrm{CO}_{2}$}

At present, cubic EoSs is mainly used to determine the phase state of fluids, among which the Peng-Kwong (PK) EoS, Soave-Redlich-Kwong (SRK) EoS, Peng-Robinson EoS, and experience Redlich-Kwong (EXP-RK) EoS are relatively typical. Comparative analysis shows that the Peng-Robinson EoS has the highest accuracy for calculating density of $\mathrm{CO}_{2}$ under different temperatures and pressure $^{18,19}$. The Peng-Robinson EoS is expressed as follows $^{20}$

$$
P=\frac{R T}{V-b}-\frac{a(T)}{V(V+b)+b(V-b)},
$$

where

$$
\left\{\begin{array}{l}
a(T)=0.457235 R^{2} T_{\text {cri }}^{2} \alpha(T) / P_{\text {cri }}, \\
\left.\alpha(T)=\left[1+0.37646+1.5426 \omega-0.26992 \omega^{2}\right)\left(1-\sqrt{T_{t}}\right)\right]^{2}, \\
b=0.077796 R T_{\text {cri }} / P_{\text {cri }}, \\
T_{\mathrm{r}}=T / T_{\text {cri }} .
\end{array}\right.
$$

Here $R$ is the universal gas constant $(8.314 \mathrm{~J} /(\mathrm{mol} \mathrm{K})), a$ and $b$ are parameters of the EoS, $P_{\text {cri }}$ the critical pressure of the $\mathrm{CO}_{2}$ phase, $T_{\text {cri }}$ the critical temperature of the $\mathrm{CO}_{2}$ phase, $w$ the eccentric factor (0.239) and $T_{\mathrm{r}}$ is the reduced temperature.

By substituting the $\mathrm{CO}_{2}$ density $\rho_{\mathrm{c}}=m / V$ into eq. (1) it can be simplified as follows

$$
\begin{gathered}
\left(b^{3} P+b^{2} R T-a b\right) \rho_{\mathrm{c}}^{3}-\left(3 b^{2} P+2 b R T-a\right) M_{\mathrm{c}} \rho_{\mathrm{c}}^{2} \\
\quad+(P b-R T) M_{\mathrm{c}}^{2} \rho_{\mathrm{c}}+P M_{c}^{3}=0,
\end{gathered}
$$

where $\rho_{\mathrm{c}}$ is the $\mathrm{CO}_{2}$ density and $M_{\mathrm{c}}$ is the molar mass of $\mathrm{CO}_{2}$.

Equation (3) is a simple cubic equation of $\rho_{\mathrm{c}}$ with three roots by which the phase state of $\mathrm{CO}_{2}$ can be determined $^{21}$. If the roots of eq. (3) consist of a real number and two imaginary numbers, the phase of $\mathrm{CO}_{2}$ is gas or liquid, determined by the temperature and pressure. If the roots of eq. (3) are three different real numbers, two phases of gas and liquid of $\mathrm{CO}_{2}$ exist at the same time. The maximum root is the density of liquid $\mathrm{CO}_{2}$, the minimum root is the density of gaseous $\mathrm{CO}_{2}$, and the middle root has no physical significance. If the three roots are equal, the $\mathrm{CO}_{2}$ fluid is in a supercritical phase, and the root value is the density of the supercritical $\mathrm{CO}_{2}$. Figure $1 a$ shows the density of $\mathrm{CO}_{2}$ in gaseous, liquid and supercritical states calculated by the Peng-Robinson EoS. The figure illustrates that the density of $\mathrm{CO}_{2}$ is highly sensitive to changes of temperature and pressure. Near the critical point, the density of $\mathrm{CO}_{2}$ changes drastically with change in temperature and pressure because the phase of $\mathrm{CO}_{2}$ changes near the critical point.

\section{Calculation model for dynamic viscosity of $\mathrm{CO}_{2}$}

The dynamic viscosity of $\mathrm{CO}_{2}$ is a function of temperature and pressure. The phases of $\mathrm{CO}_{2}$ are different under different temperatures and pressures, and the dynamic viscosities of gaseous and liquid $\mathrm{CO}_{2}$ are usually calculated using different models. In the continuous transition of $\mathrm{CO}_{2}$ from gas to liquid, conventional methods of 

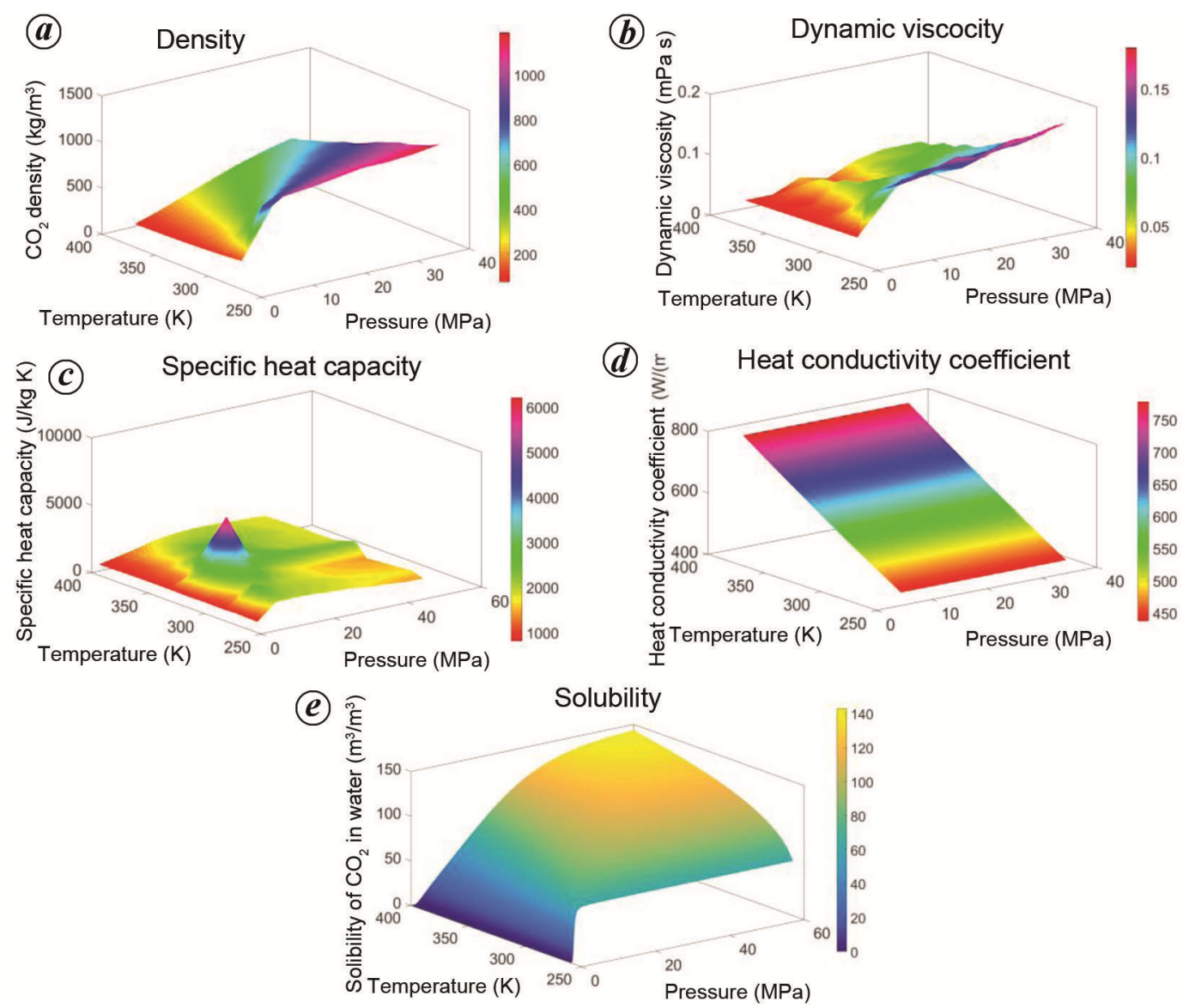

Figure $1 \boldsymbol{a}-\boldsymbol{e}$. Relationship between thermodynamic parameters of carbon dioxide $\left(\mathrm{CO}_{2}\right)$ and pressure and temperature.

calculation are no longer applicable for the dynamic viscosity of $\mathrm{CO}_{2}$. Based on the Peng-Robinson EoS, a new calculation model for dynamic viscosity was established $^{25}$ which can be used to calculate the dynamic viscosity of $\mathrm{CO}_{2}$ in the gas, liquid and supercritical phases. The formula for $\mathrm{CO}_{2}$ dynamic viscosity can be expressed as follows ${ }^{22-24}$

$$
T \mu_{\mathrm{c}}^{3}+\left(2 b T-b^{\prime} T-r^{\prime} P\right) \mu_{\mathrm{c}}^{2}-
$$$$
\left(2 b b^{\prime} T+T b^{2}+2 r^{\prime} b P-a\right) \mu_{\mathrm{c}}+\left(T b^{\prime} b^{2}+r^{\prime} P b^{2}-a b^{\prime}\right)=0,
$$

where

$$
\begin{aligned}
a & =0.45724 r_{\mathrm{c}}^{2} P_{\mathrm{c}}^{2} / T_{\mathrm{c}}^{2}, b=0.07780 r_{\mathrm{c}}^{2} P_{\mathrm{c}}^{2} / T_{\mathrm{c}}^{2}, \\
\mu_{\mathrm{c}} & =7.7 T_{\mathrm{c}}^{-1 / 6} M^{0.5} P_{\mathrm{c}}^{2 / 3}, \\
r^{\prime} & =r \tau\left(T_{\mathrm{r}}, P_{\mathrm{r}}\right), b^{\prime}=b \phi \tau\left(T_{\mathrm{r}}, P_{\mathrm{r}}\right), \tau\left(T_{\mathrm{r}}, P_{\mathrm{r}}\right) \\
& =\left[1+Q_{1}\left(\sqrt{P_{\mathrm{r}} T_{\mathrm{r}}-1}\right)\right]^{-2}, \\
P_{\mathrm{r}} & =P / P_{\mathrm{c}}, T_{\mathrm{r}}=T / T_{\mathrm{c}}, \\
Q_{1} & =0.829599+0.350867 w-0.747680 w^{2},
\end{aligned}
$$

$\mu_{\mathrm{c}}$ is the dynamic viscosity of $\mathrm{CO}_{2}$, and $\phi$ is the pore ratio.
Figure $1 b$ shows the results of applying eq. (4) to calculate the dynamic viscosity of $\mathrm{CO}_{2}$ fluid under different temperatures and pressures.

\section{Calculation model for specific heat capacity of $\mathrm{CO}_{2}$}

The calculation models for $\mathrm{CO}_{2}$ specific heat capacity can be classified into two categories: models for gaseous $\mathrm{CO}_{2}$ and those for liquid $\mathrm{CO}_{2}$. The Sterling-Brown equation is generally used to calculate the specific heat capacity of liquid $\mathrm{CO}_{2}$. Because of the phase change of $\mathrm{CO}_{2}$, a calculation model for the specific heat capacity of $\mathrm{CO}_{2}$ in different phases should be selected. We used the calculation model for specific heat capacity of $\mathrm{CO}_{2}$ based on the Peng-Robinson EoS; it can be used to calculate the specific heat capacity of $\mathrm{CO}_{2}$ in any phase and is expressed as follows ${ }^{25,26}$

$$
\begin{aligned}
C_{\mathrm{pc}}= & C_{\mathrm{p}}^{*}+D C_{\mathrm{p}}=C_{\mathrm{p}}^{*}+(Z-1) R \\
& +\frac{0.6766 P}{Z R T^{2}+29.7903 \times 10^{-6} P T},
\end{aligned}
$$

where $C_{\mathrm{pc}}$ is the specific heat capacity of the fluid at constant pressure, $\Delta C_{\mathrm{p}}$ the deviation of specific heat capacity 


\section{RESEARCH ARTICLES}

at constant pressure, $Z$ the compressibility factor $(Z=P V / R T), T$ the temperature and $C_{\mathrm{p}}^{*}$ is the specific heat capacity of an ideal gas under constant pressure, given by $C_{\mathrm{p}}^{*}=A+B T+C T^{2}+D T^{3}$, where $A=4.728$, $B=1.754 \times 10^{-2}, \quad C=-2.338 \times 10^{-5}, \quad$ and $D=4.079 \times$ $10^{-9}$.

In general, the injection pressure of $\mathrm{CO}_{2}$ is $5-35 \mathrm{MPa}$, and the injection temperature is $253-393 \mathrm{~K}$. Figure $1 c$ shows the calculated specific heat capacities of $\mathrm{CO}_{2}$ under different pressures and temperatures using eq. (5). The figure illustrates that a peak point of the specific heat capacity of $\mathrm{CO}_{2}$ occurs near the critical region. This indicates that the phase change of $\mathrm{CO}_{2}$ has a great effect on its specific heat capacity.

\section{Calculation model for heat conductivity coefficient of $\mathrm{CO}_{2}$}

The heat conductivity coefficient of $\mathrm{CO}_{2}$ is a function of temperature and pressure. Under different temperatures and pressures, the heat conductivity coefficient changes with the $\mathrm{CO}_{2}$ phase. We used the calculation model for heat conductivity of $\mathrm{CO}_{2}$ as follows ${ }^{23,27}$

$$
\begin{aligned}
& \left(\lambda_{\mathrm{c}}-\lambda_{\mathrm{c} 0}\right) \Gamma Z_{\mathrm{c}}^{5} \\
& \quad=\left\{\begin{array}{l}
1.22 \times 10^{-2}\left(\mathrm{e}^{0.535 \rho_{\mathrm{r}}}-1\right), \rho_{\mathrm{r}}<0.5, \\
1.14 \times 10^{-2}\left(\mathrm{e}^{0.67 \rho_{\mathrm{r}}}-1.069\right), 0.5 \leq \rho_{\mathrm{r}} \leq 2.0, \\
2.60 \times 10^{-3}\left(\mathrm{e}^{1.155 \rho_{\mathrm{r}}}+2.016\right), 2.0<\rho_{\mathrm{r}}<2.8,
\end{array}\right.
\end{aligned}
$$

where $\lambda_{c 0}$ is the heat conductivity of supercritical $\mathrm{CO}_{2}$ at atmospheric pressure

$$
\lambda_{c 0}=10^{\left(1.307 \log _{10} T-0.5\right)} \text { and } \Gamma=1.431 \times 10^{7}\left(T_{\text {cri }} M^{3} / \rho_{\text {cri }}^{4}\right)^{1 / 6}
$$

Figure $1 d$ shows the calculation model for heat conductivity coefficient of $\mathrm{CO}_{2}$. The figure indicates that temperature and pressure have significant effects on the heat conductivity of $\mathrm{CO}_{2}$. The heat conductivity coefficient of $\mathrm{CO}_{2}$ in the energy conservation equation should be modified by the calculation model of eqs (6) to (7) account for changes in temperature and pressure in the reservoir during the migration of $\mathrm{CO}_{2}$ in saline aquifers.

\section{Solubility of $\mathrm{CO}_{2}$ in saline water}

The solubility of $\mathrm{CO}_{2}$ in brine is non-negligible with an increase in temperature and pressure ${ }^{28}$. We used the calculation model for solubility of $\mathrm{CO}_{2}$ in brine as follows ${ }^{29}$

$$
\rho_{\mathrm{dc}}=\frac{0.178094}{\left[\begin{array}{c}
A_{1} \rho_{w}^{A_{2}}(1.8 T-459.67)^{A_{7}}+A_{3}(1.8 T-459.67)^{A_{4}} \\
\times \exp \left[-145.0377 A_{5} p+A_{6} /(145.0377 p)\right]
\end{array}\right]},
$$

where $\rho_{\mathrm{dc}}$ is the $\mathrm{CO}_{2}$ solubility in brine and $A_{1}, A_{2}, A_{3}, A_{4}$, $A_{5}, A_{6}$ and $A_{7}$ are the parameters of the calculation model, whose values are $0.004934,4.0928,5.71 \times 10^{-7}, 1.6428$, $6.763 \times 10^{-4}, 781.334$ and -0.2499 respectively.

\section{The THM coupled modelling framework}

\section{Mass conservation equation}

During the flow of water and $\mathrm{CO}_{2}$ in saline aquifers, the dissolution of water and $\mathrm{CO}_{2}$ in each other will occur. If the dissolution of water in $\mathrm{CO}_{2}$ is ignored and only the dissolution of $\mathrm{CO}_{2}$ in water is considered, the mass conservation equations for water and $\mathrm{CO}_{2}$ can be written as follows

$$
\left\{\begin{array}{l}
\underbrace{\frac{\partial\left(\phi S_{w} \rho_{\mathrm{w}}\right)}{\partial t}+\nabla\left(\rho_{\mathrm{w}} \vec{v}_{\mathrm{w}}\right)=0}_{\text {Liquid water }} \\
\underbrace{\frac{\partial\left(\phi\left(1-S_{\mathrm{w}}\right) \rho_{\mathrm{c}}\right)}{\partial t}+\nabla\left(\rho_{\mathrm{c}} \vec{v}_{\mathrm{c}}\right)}_{\text {Supercritical/liquid/gas } \mathrm{CO}_{2}}+\underbrace{\frac{\partial\left(\phi S_{\mathrm{w}} \rho_{d c}\right)}{\partial t}+\nabla\left(\rho_{d c} \vec{v}_{\mathrm{c}}\right)}_{\text {Dissolved } \mathrm{CO}_{2} \text { in water }}=0,
\end{array}\right.
$$

where $\phi$ is the porosity of the saline aquifer, $S_{\mathrm{w}}$ the water saturation, $\rho_{\mathrm{w}}$ the density of water, $\rho_{\mathrm{w}}$ the velocity of water, $t$ the time, $\rho_{\mathrm{c}}$ is the density of $\mathrm{CO}_{2}$, which is determined by the reservoir temperature and pressure and can be calculated by eq. (3), $v_{\mathrm{c}}$ is the velocity of $\mathrm{CO}_{2}$ and $\rho_{\mathrm{dc}}$ is the dissolution of $\mathrm{CO}_{2}$ in water which is calculated by eq. (7).

The flow of water and $\mathrm{CO}_{2}$ in porous media is governed by the generalized Darcy's law. The corresponding formula for fluid velocity is as follows

$$
\boldsymbol{v}_{\mathrm{w}, \mathrm{c}}=-\frac{\boldsymbol{k} \boldsymbol{k}_{\mathrm{rw}, \mathrm{c}}}{\mu_{\mathrm{w}, \mathrm{c}}} \nabla\left(p_{w, c}-\rho_{w, c} \boldsymbol{g}\right),
$$

where $\boldsymbol{k}$ is the intrinsic permeability of rock, $k_{\mathrm{rw}}$ and $k_{\mathrm{rc}}$ the relative permeability of water and $\mathrm{CO}_{2}$ respectively, $\mu_{\mathrm{w}}$ the dynamic viscosity of water, $\mu_{\mathrm{c}}$ the dynamic viscosity of $\mathrm{CO}_{2}$, which can be calculated by eq. (4), and $\boldsymbol{g}$ is the acceleration due to gravity.

The density of water is influenced by pressure and temperature. The relationship of water density $\rho_{\mathrm{w}}$ with pressure and temperature can be expressed as follows

$$
p_{\mathrm{w}}=p_{\mathrm{w} 0} \exp \left[c_{\mathrm{wp}}\left(p_{\mathrm{w}}-p_{\mathrm{wref}}\right)-c_{\mathrm{wT}}\left(T_{\mathrm{w}}-T_{\mathrm{wref}}\right)\right],
$$

and

$$
\left\{\begin{array}{l}
c_{\mathrm{wp}}=\frac{1}{\rho_{\mathrm{w}}} \frac{\partial \rho_{\mathrm{w}}}{\partial p_{\mathrm{w}}} \\
c_{\mathrm{wT}}=-\frac{1}{\rho_{\mathrm{w}}} \frac{\partial \rho_{\mathrm{w}}}{\partial T}
\end{array}\right.
$$


where $p_{\text {wref }}$ is the reference pressure whose value is $101.325 \mathrm{kPa}$ under standard conditions, $T_{\text {wref }}$ the reference temperature, whose value is $273 \mathrm{~K}$ under standard conditions and $\rho_{\mathrm{w} 0}$ is the density of water under reference pressure and reference temperature.

\section{Energy conservation equation}

Heat exchange occurs within the system composed of water, $\mathrm{CO}_{2}$ and saline aquifers by convection and heat transfer. To more accurately simulate the effect of the temperature field on $\mathrm{CO}_{2}$ sequestration, the physical properties of $\mathrm{CO}_{2}$, such as specific heat capacity and heat conductivity were considered in this study. Based on the law of energy conservation, the energy balance equation of the temperature field can be written as follows ${ }^{30}$

$$
\begin{gathered}
\frac{\partial}{\partial t}\left[\left(\rho C_{\mathrm{p}}\right)_{\mathrm{e}} T\right]+\left(\vec{v}_{\mathrm{w}} \rho_{\mathrm{w}} C_{\mathrm{pw}}+\vec{v}_{\mathrm{c}} \rho_{\mathrm{c}} C_{\mathrm{pc}}\right) \nabla T \\
-\nabla \cdot\left(\lambda_{\mathrm{e}} \nabla T\right)=Q_{T},
\end{gathered}
$$

and

$$
\left\{\begin{array}{l}
\left(\rho C_{\mathrm{p}}\right)_{\mathrm{e}}=\phi\left(S_{\mathrm{w}} \rho_{\mathrm{w}} C_{\mathrm{pw}}+S_{\mathrm{c}} p_{\mathrm{c}} C_{\mathrm{pc}}\right)+(1-\phi) \rho_{\mathrm{s}} C_{\mathrm{ps}} \\
\lambda_{\mathrm{e}}=\phi\left[S_{\mathrm{w}} \lambda_{\mathrm{w}}+\left(1-S_{\mathrm{w}}\right) \lambda_{\mathrm{c}}\right]+(1-\phi) \lambda_{\mathrm{s}} \\
Q_{\mathrm{T}}=\phi Q_{\mathrm{f}}+(1-\phi) Q_{\mathrm{s}} \\
\overrightarrow{\boldsymbol{v}}_{\mathrm{w}, \mathrm{c}}=-\frac{\boldsymbol{k} k_{\mathrm{rw}, \mathrm{c}}}{\mu_{\mathrm{w}, \mathrm{c}}}\left(\nabla p_{\mathrm{w}, \mathrm{c}}-\rho_{\mathrm{w}, \mathrm{c}} \boldsymbol{g}\right)
\end{array},\right.
$$

where $\left(\rho C_{\mathrm{p}}\right)_{\mathrm{e}}$ is the effective heat capacity of the porous medium, $C_{\mathrm{pw}}, C_{\mathrm{pc}}$ and $C_{\mathrm{ps}}$ are the specific heat capacity of water specie, $\mathrm{CO}_{2}$ specie and porous media respectively, and $C_{\mathrm{pc}}$ can be calculated by eq. (5), $\lambda_{\mathrm{e}}$ is the effective heat conductivity coefficient, $\lambda_{\mathrm{w}}, \lambda_{\mathrm{c}}$ and $\lambda_{\mathrm{s}}$ are the heat conductivity coefficient of water specie, $\mathrm{CO}_{2}$ specie and porous media respectively, and $\lambda_{\mathrm{c}}$ can be calculated by eq. (6) and $Q_{\mathrm{f}}$ and $Q_{\mathrm{s}}$ are the heat source and heat sink of fluid and porous medium respectively, and $Q_{\mathrm{f}}=Q_{\mathrm{s}}=0$ when the heat source and heat sink of rock are ignored.

\section{Equation of mechanical balance}

Reservoirs are usually porous media, the mechanical properties of which are influenced by pore characteristics, pore fluid pressure and reservoir temperature. Porous medium is generally considered to be a linearly elastic material. According to the generalized Hooke's law, the control equation of the stress field expressed by the displacement, pore fluid pressure $p$ and change in temperature $T$ can be written as follows ${ }^{30}$

$$
G u_{i, j j}+(G+\lambda) u_{j, j i}+\alpha_{p} p_{, i}+\alpha_{T} T_{, i}+F_{i}=0,
$$

and

$$
\left\{\begin{array}{l}
G=E /[2(1+v)] \\
\lambda=E v /[(1+v)(1-2 v)] \\
p=S_{\mathrm{w}} p_{\mathrm{w}}+\left(1-S_{\mathrm{w}}\right) p_{\mathrm{c}} \\
F_{i}=\rho g \\
\rho=(1-n) \rho_{\mathrm{s}}+n S_{\mathrm{w}} \rho_{\mathrm{w}}+n\left(1-S_{\mathrm{w}}\right) \rho_{\mathrm{c}}
\end{array}\right.
$$

where $G$ is the shear modulus, $u_{i}$ the displacement component in the $i$ th direction $(i=x, y, z), \lambda$ the lame constant, $\alpha_{\mathrm{p}}(\leq 1)$ the corresponding Biot effective stress coefficient of the pore, $p_{, i}$ the pore pressure, $\alpha_{\mathrm{T}}$ is the thermal expansion coefficient, $T_{, i}$ the change of the reservoir temperature, $F_{i}$ the volume force in the $i$ th direction, $E$ the elastic modulus of the reservoir and $v$ is the Poisson ratio.

\section{Dynamic evolution model of porosity and permeability}

The porosity and permeability of a reservoir are key factors to describe fluid flow within the rock strata, which are closely related to the stress state and intrinsic properties of the rocks. The porosity and permeability of rock strata are influenced by ground stress, pore pressure and temperature. Considering the volume deformation caused by change in the framework particles and temperature, dynamic evolution models for porosity and absolute permeability respectively, can be represented as follows ${ }^{31}$

$$
\begin{aligned}
& \varphi=1-\frac{\left(1-\varphi_{0}\right)\left(1-\Delta p / K_{\mathrm{s}}+\alpha_{\mathrm{T}} \Delta T\right)}{1+\varepsilon_{v}}, \\
& k=\frac{k_{0}}{1+\varepsilon_{v}}\left[1+\frac{\varepsilon_{v}-\left(1-\varphi_{0}\right)\left(\alpha_{T} \Delta T+\Delta p / K_{\mathrm{s}}\right)}{\varphi_{0}}\right]^{3},
\end{aligned}
$$

where $\varphi_{0}$ is the initial porosity of the reservoir, $\varepsilon_{v}=\varepsilon_{\mathrm{x}}+\varepsilon_{\mathrm{y}}+\varepsilon_{\mathrm{z}}$ the volume strain of the reservoir, $\Delta p$ the increment of the pore pressure, $\Delta T$ the increment of temperature, $K_{\mathrm{s}}$ the volume modulus of the reservoir framework, and $k_{0}$ the initial absolute permeability of the strata.

Currently, the relative permeability models for porous media include the Van Genuchten Mulaem/Burdine (VGM\&VGB) model, the Brooks and Corey Mulaem/ Burdine (BCM\&BCB) model, the lognormal distributionMualem (LNM) model, the Brutsaert-Burdine (BRB) model, and the Gardner-Mulaem model (GDM), among others. Among these, the VGM and $\mathrm{BCB}$ models are popular. The BCB model was selected to calculate relative permeability of water and $\mathrm{CO}_{2}$ phase in this study, and the corresponding equations are given below ${ }^{32,33}$

$$
k_{\mathrm{r}, \mathrm{w}}=k_{\mathrm{r}, \mathrm{w} 0}\left(\frac{S_{\mathrm{w}}-S_{\mathrm{r}, \mathrm{w}}}{1-S_{\mathrm{r}, \mathrm{w}}-S_{\mathrm{r}, \mathrm{c}}}\right)^{3+\frac{2}{\lambda}}
$$




$$
k_{\mathrm{r}, \mathrm{c}}=k_{\mathrm{r}, \mathrm{c} 0}\left(1-\frac{S_{\mathrm{w}}-S_{\mathrm{r}, \mathrm{w}}}{1-S_{\mathrm{r}, \mathrm{w}}-S_{\mathrm{r}, \mathrm{c}}}\right)^{2}\left[1-\left(\frac{S_{\mathrm{w}}-S_{\mathrm{r}, \mathrm{w}}}{1-S_{\mathrm{r}, \mathrm{w}}-S_{\mathrm{r}, \mathrm{c}}}\right)^{1+\frac{2}{\lambda}}\right],
$$

where $k_{\mathrm{r}, \mathrm{w} 0}$ is the initial relative permeability of the water phase, $k_{\mathrm{r}, \mathrm{co}}$ the initial relative permeability of the $\mathrm{CO}_{2}$ phase, $S_{\mathrm{r}, \mathrm{w}}$ residual saturation of the water phase, $S_{\mathrm{r}, \mathrm{c}}$ residual saturation of the $\mathrm{CO}_{2}$ phase and $\lambda$ is a parameter representing the characteristics of pore structure in the reservoir.

\section{Model verification}

\section{Computational procedure}

Methods to calculate density, dynamic viscosity, specific heat capacity, heat conductivity coefficient, and dissolution of $\mathrm{CO}_{2}$ under different temperatures and pressures are included in the proposed model. The deformation control equation of solid mechanics, the equation of motion of two-phase flow and the control equation of temperature fields based on energy conservation are also included in the model. The evaluation laws of porosity, absolute permeability, relative permeability and capillary force of rock strata at any given time are involved in the above three control equations. The pore pressure, strata deformation and fluid saturation at different times can be obtained by solving the THM coupled model using the finite element method (FEM). The fluid flow in rock strata will change the porosity, permeability and capillary force of the rocks. As a result, solution of the THM coupled model is nonlinear and an iterative method should be employed. COMSOL Multiphysics is a commercial software that can be used to numerically solve the PDE equation of the THM coupled model.

\section{Verification of the fully coupled model}

In $\mathrm{CO}_{2}$ sequestration, migration velocity is measured by the horizontal distance between the intersection point of the $\mathrm{CO}_{2}$-brine interface and the upper boundary of the aquifer to the well. The horizontal distance is referred to as the distance of the $\mathrm{CO}_{2}$ migration front. The spatial distribution and distance of the $\mathrm{CO}_{2}$ front in its sequestration were used to verify the THM model in this study. The parameters of the reservoir used to sequestrate $\mathrm{CO}_{2}$ were as follows: length of the reservoir was $1000 \mathrm{~m}$, thickness was $100 \mathrm{~m}$, burial depth was $1500 \mathrm{~m}$, and upper and bottom boundaries of the reservoir were impermeable. $\mathrm{CO}_{2}$ was injected into the reservoir at a flow rate of $1 \mathrm{Mt} /$ year. Figure $2 a$ shows the spatial distribution of $\mathrm{CO}_{2}$ one year after injection ${ }^{34}$. Figure $2 b$ shows $\mathrm{CO}_{2}$ distribution obtained by solving the THM coupled model under the same conditions. The distribution characteristics of $\mathrm{CO}_{2}$ in Figure $2 a$ and $b$ are the same. The distance of $\mathrm{CO}_{2}$ migration front calculated by the THM coupled model was $618 \mathrm{~m}$, which is close to the value $(620 \mathrm{~m})$ calculated by Vilarrasa et $a l .{ }^{34}$. This difference between the two calculated distances of the $\mathrm{CO}_{2}$ migration front is because continuous variation of density, dynamic viscosity, specific heat capacity, heat conductivity coefficient and solubility of $\mathrm{CO}_{2}$ in water were considered in the THM coupled model. Figure 2 shows that the spatial distribution and migration velocity of $\mathrm{CO}_{2}$ in the aquifer can be precisely predicted by the established THM coupled model. The figure also indicates that it is reliable and viable to study complex $\mathrm{CO}_{2}$ injection by the THM coupled model.

\section{Thermodynamic effect of supercritical $\mathrm{CO}_{2}$ sequestration}

Mathematical model and calculation parameters: The thickness of the saline aquifer was $100 \mathrm{~m}$ and burial depth was $1000 \mathrm{~m}$. The hydrostatic pressure gradient within the aquifer was $0.01 \mathrm{MPa} / \mathrm{m}$ and the geothermal gradient was $0.01 \mathrm{~K} / \mathrm{m}$. The diameter of the $\mathrm{CO}_{2}$ injection borehole was $0.1 \mathrm{~m}$. As shown in Figure 3, the aquifer was located in the two-dimensional $X-Z$ plane. The size of the aquifer was $1200 \mathrm{~m} \times 100 \mathrm{~m}$. The solved region

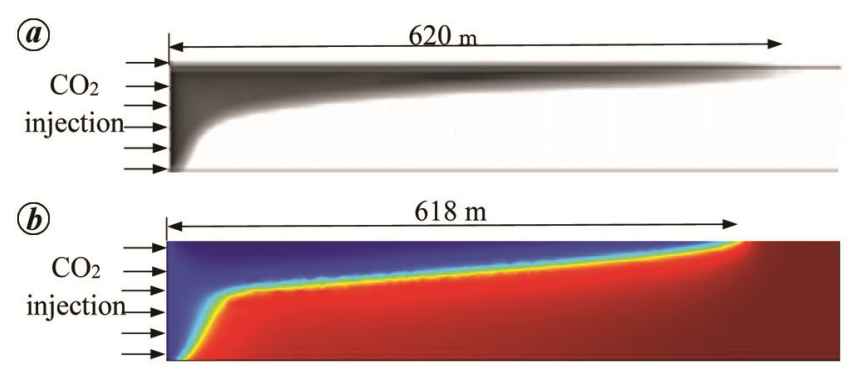

Figure 2. Spatial distribution and front distance of $\mathrm{CO}_{2}$ migration within the reservoir after one year of $\mathrm{CO}_{2}$ injection. $\boldsymbol{a}$, Results using the method of Vilarrasa et $a .^{34}$. $\boldsymbol{b}$, Results using the thermo-hydromechanical (THM) coupling model.

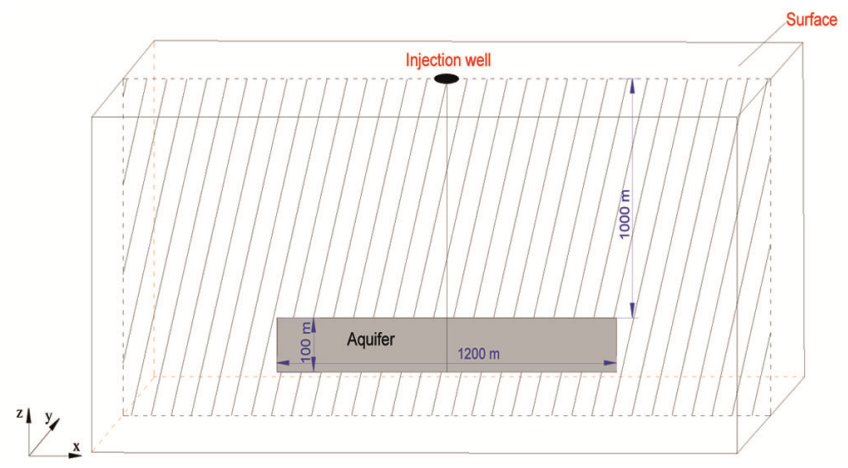

Figure 3. Schematic diagram of the $2 \mathrm{D}$ calculation region.

CURRENT SCIENCE, VOL. 119, NO. 6, 25 SEPTEMBER 2020 
Table 1. Numerical simulation parameters

\begin{tabular}{|c|c|c|}
\hline Parameter & Value & Source \\
\hline Elastic modulus of the reservoir $(E)$ & $10 \mathrm{GPa}$ & 18 \\
\hline Reservoir Poisson's ratio $(v)$ & 0.3 & 18 \\
\hline Reservoir density $\left(\rho_{\mathrm{s}}\right)$ & $2200 \mathrm{~kg} / \mathrm{m}^{3}$ & 18 \\
\hline Reservoir specific heat capacity $\left(C_{\mathrm{s}}\right)$ & $0.85 \mathrm{~kJ} /(\mathrm{kg} \mathrm{K})$ & 18 \\
\hline Reservoir heat conductivity coefficient $\left(\lambda_{\mathrm{s}}\right)$ & $2.5 \mathrm{w} /(\mathrm{m} \mathrm{k})$ & 11 \\
\hline Reservoir heat expansion coefficient $\left(\alpha_{\mathrm{s}}\right)$ & $1 \times 10^{-5} 1 / \mathrm{K}$ & 11 \\
\hline Initial porosity of the reservoir $\left(\varphi_{0}\right)$ & 0.2 & 18 \\
\hline Initial permeability of the reservoir $\left(k_{0}\right)$ & $1 \times 10^{-16} \mathrm{~m}^{2}$ & 18 \\
\hline Reservoir temperature $(\mathrm{T})$ & $273-373 \mathrm{~K}$ & 18 \\
\hline Hydrostatic pressure $\left(p_{0}\right)$ & $5-25 \mathrm{MPa}$ & 18 \\
\hline Biot's coupled coefficient $\left(\alpha_{\mathrm{p}}\right)$ & 1 & 18 \\
\hline $\begin{array}{l}\text { Characteristic parameter of reservoir pore } \\
\text { construct }(\lambda)\end{array}$ & 1 & 33 \\
\hline Density of water $\left(\rho_{\mathrm{w}}\right)$ & $1000 \mathrm{~kg} / \mathrm{m}^{3}$ & 5 \\
\hline Dynamic viscosity of water $\left(\mu_{\mathrm{w}}\right)$ & $0.283 \mathrm{mPa} \mathrm{s}$ & 5 \\
\hline Specific heat capacity $\left(C_{p w}\right)$ & $4.2 \mathrm{~kJ} /(\mathrm{kg} \mathrm{K})$ & 5 \\
\hline Heat conductivity of water $\left(\lambda_{\mathrm{w}}\right)$ & $0.67 \mathrm{w} /(\mathrm{m} \mathrm{k})$ & 5 \\
\hline Residual saturation of water $\left(S_{\mathrm{r}, \mathrm{w}}\right)$ & 0.05 & 18 \\
\hline Compressibility factor of water $\left(c_{w p}\right)$ & $1 \times 10^{-9} 1 / \mathrm{Pa}$ & 11 \\
\hline Heat expansion coefficient of water $\left(c_{\mathrm{wpT}}\right)$ & $4.5 \times 10^{-5} 1 / \mathrm{K}$ & 11 \\
\hline Density of $\mathrm{CO}_{2}\left(\rho_{\mathrm{c}}\right)$ & \multicolumn{2}{|c|}{ Calculated by continuous model in part 2.1} \\
\hline Dynamic viscosity of $\mathrm{CO}_{2}\left(\mu_{\mathrm{c}}\right)$ & \multicolumn{2}{|c|}{ Calculated by continuous model in part 2.2} \\
\hline Specific heat capacity of $\mathrm{CO}_{2}\left(C_{\mathrm{pc}}\right)$ & \multicolumn{2}{|c|}{ Calculated by continuous model in part 2.3} \\
\hline Heat conductivity coefficient of $\mathrm{CO}_{2}\left(\lambda_{\mathrm{c}}\right)$ & \multicolumn{2}{|c|}{ Calculated by continuous model in part 2.4} \\
\hline Solubility of $\mathrm{CO}_{2}$ in water $\left(\rho_{\mathrm{dc}}\right)$ & \multicolumn{2}{|c|}{ Calculated by continuous model in part 2.5} \\
\hline Residual saturation of $\mathrm{CO}_{2}\left(S_{\mathrm{r}, \mathrm{c}}\right)$ & 0.05 & 18 \\
\hline Mass flow rate of $\mathrm{CO}_{2}\left(q_{\mathrm{c}}\right)$ & $5 \mathrm{~kg} / \mathrm{s}$ & 18 \\
\hline
\end{tabular}

was symmetrical about the injection borehole. To reduce the mesh element size and operational cost of the numerical simulation, a region with size $600 \mathrm{~m} \times 100 \mathrm{~m}$ to the right of the injection well was selected as the solution region. Table 1 shows the related parameters of the numerical simulation.

\section{Injection pressure of $\mathrm{CO}_{2}$ under the THM coupled model}

The injection pressure of $\mathrm{CO}_{2}$ is the difference in pressure at the $\mathrm{CO}_{2}$ injection point and the initial hydrostatic pressure or pore water pressure. The corresponding expression is ${ }^{34}$

$$
p_{\text {inj }}=p_{\text {c,inj }}-p_{\text {hyd,inj }},
$$

where $p_{\text {inj }}$ is the injection pressure of $\mathrm{CO}_{2}, p_{\mathrm{c}, \text { inj }}$ the pressure of $\mathrm{CO}_{2}$ at the injection point and $p_{\text {hyd,inj }}$ is the initial hydrostatic pressure or pore water pressure.

Figure 4 shows the comparison results of $\mathrm{CO}_{2}$ injection pressure calculated by the THM coupled model and the uncoupled model established by Sasaki et al. ${ }^{18}$. Figure $4 a$ shows that when the reservoir temperature is above $380 \mathrm{~K}$, the $\mathrm{CO}_{2}$ injection pressure calculated by the ideal gas EoS is close to the $\mathrm{CO}_{2}$ injection pressure calculated by the Span and Wagner EoS. When the reservoir temperature is close to the critical temperature, the $\mathrm{CO}_{2}$ injection pressure calculated by the ideal gas EoS is larger than that calculated by the Span and Wagner EoS.

As shown in Figure $4 b$ and $c$, the predicted $\mathrm{CO}_{2}$ injection pressure by the THM coupled model is higher than that calculated by the uncoupled model. At a constant reservoir pressure and reservoir temperatures above $380 \mathrm{~K}$, the difference between the two predicted $\mathrm{CO}_{2}$ injection pressures decreases with increase in reservoir temperature. At a constant reservoir temperature, the difference of the two predicted values decreases with increase in reservoir pressure. Moreover, when the reservoir condition is close to the critical point of $\mathrm{CO}_{2}$, the difference between the two predicted $\mathrm{CO}_{2}$ injection pressures is relatively large because the phase change of $\mathrm{CO}_{2}$ affects its injection pressure.

The preceding analysis shows that: (i) the injection pressure of $\mathrm{CO}_{2}$ is highly sensitive to the reservoir temperature and pressure, and this is more obvious when the reservoir condition is close to the critical point of $\mathrm{CO}_{2}$ and (ii) the injection pressure of $\mathrm{CO}_{2}$ calculated by the uncoupled model, which is based on the ideal gas EoS, and Span and Wagner EoS is lower than that calculated by the THM coupled model. The calculation of the physical properties of $\mathrm{CO}_{2}$, the phase of which continuously changes, has been taken into consideration in the THM coupled model. As a result, the calculation results of the THM coupled model should be more accurate than that of 


\section{RESEARCH ARTICLES}
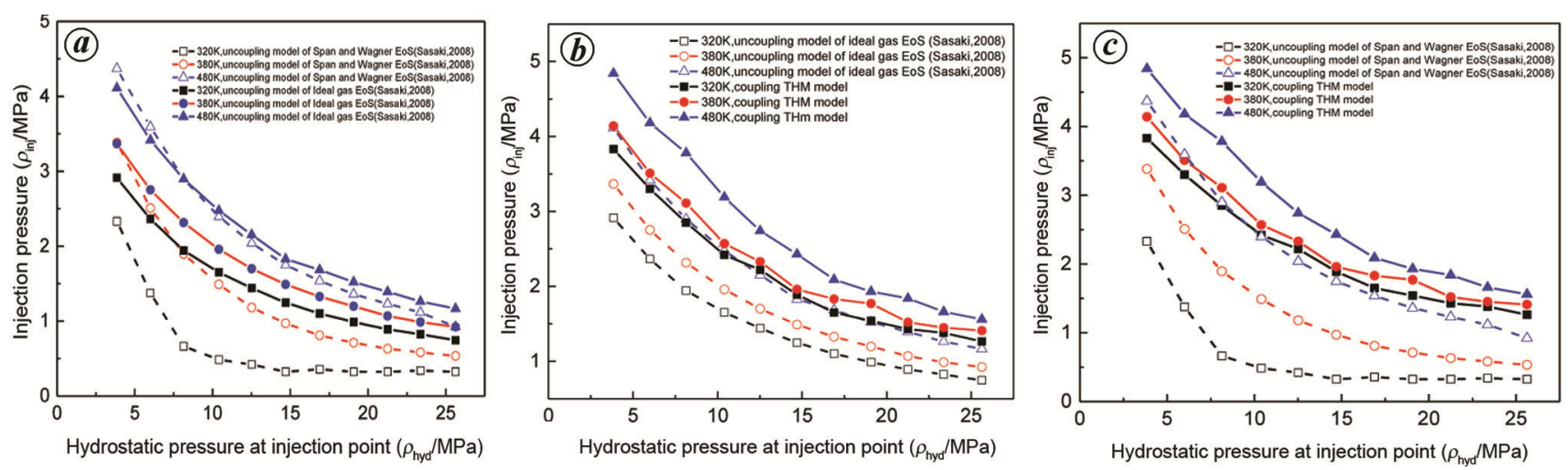

Figure 4. Relation between $\mathrm{CO}_{2}$ injection pressure, and reservoir temperature and pressure. $\boldsymbol{a}$, Comparison of injection pressure calculated by the uncoupled model based on the ideal gas equation of state (EoS) and Span and Wagner EoS ${ }^{34}$. b , Comparison of injection pressure calculated by the THM coupled model and uncoupled model based on the ideal gas EoS. $c$, Comparison of injection pressure calculated by the THM coupled model and uncoupled model based on the Span and Wagner EoS.

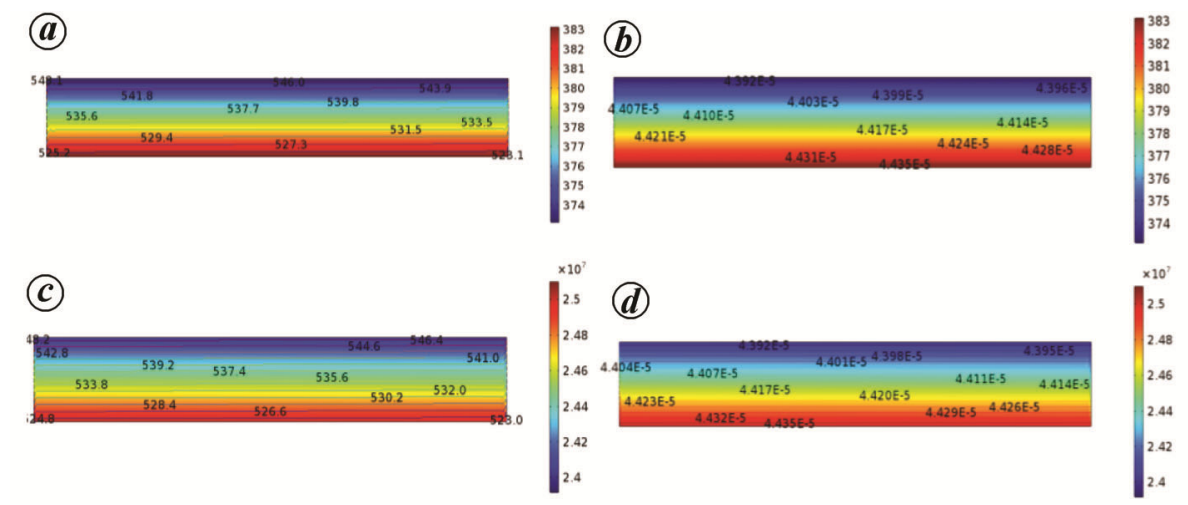

Figure 5. Density and dynamic viscosity of $\mathrm{CO}_{2}$ under different temperatures and pressures. $\boldsymbol{a}$, Nephogram of reservoir temperature and density contour of $\mathrm{CO}_{2}$. $\boldsymbol{b}$, Nephogram of reservoir temperature and dynamic viscosity contour of $\mathrm{CO}_{2}$. c, Nephogram of reservoir pressure and density contour of $\mathrm{CO}_{2}$. $\boldsymbol{d}$, Nephogram of reservoir pressure and dynamic viscosity contour of $\mathrm{CO}_{2}$.

the uncoupled model. It is necessary to verify the calculation error of the THM coupled model by field tests.

\section{Spatial distribution of $\mathrm{CO}_{2}$ in the THM coupled model}

The temperature of injected $\mathrm{CO}_{2}$ is usually lower than the reservoir temperature, and heat transfer between $\mathrm{CO}_{2}$ and the reservoir will occur until the thermal transfer reaches an equilibrium state. Due to the existence of a geothermal gradient and hydrostatic pressure gradient within the reservoir, the density and dynamic viscosity of the injected $\mathrm{CO}_{2}$ in the vertical direction is significantly different (Figure 5). After $\mathrm{CO}_{2}$ injection, the density of $\mathrm{CO}_{2}$ at the top boundary of the reservoir is larger than at the bottom boundary, whereas the dynamic viscosity of $\mathrm{CO}_{2}$ at the upper reservoir is smaller than at the lower reservoir (Figure 5).

It can be seen from Figure $6 a$ that in the migration direction of $\mathrm{CO}_{2}$, the saturation of $\mathrm{CO}_{2}$ rapidly increases to a peak value and then slowly decreases. The saturation of $\mathrm{CO}_{2}$ rapidly falls to the initial value, after which it is maintained at the same value. The saturation of $\mathrm{CO}_{2}$ at the upper boundary of the reservoir was divided into four sections along the migration direction: the fast increase section, the slow decrease section, the fast decrease section and the initial saturation section. They are shown in Figure 7 as regions I, II, III and IV respectively. These four regions change with time.

The reasons for the existence of the fast increase section are as the follows: (i) $\mathrm{CO}_{2}$ was still in a compressed state when it entered the reservoir. Since the reservoir temperature was higher than the temperature of $\mathrm{CO}_{2}$, the compressed $\mathrm{CO}_{2}$ would expand rapidly. (ii) The pressure of $\mathrm{CO}_{2}$ at the bottom of the borehole was high, and compressed $\mathrm{CO}_{2}$ was injected into the reservoir under high injection pressure. As a result, the amount of $\mathrm{CO}_{2}$ in the reservoir around the bottom of the borehole rapidly increased in a short time. With continuous injection, the compressed supercritical $\mathrm{CO}_{2}$ in the slow decrease region adapted to the reservoir environment. Finally, $\mathrm{CO}_{2}$ migrated to the fast decrease region and the initial saturation region. 
RESEARCH ARTICLES

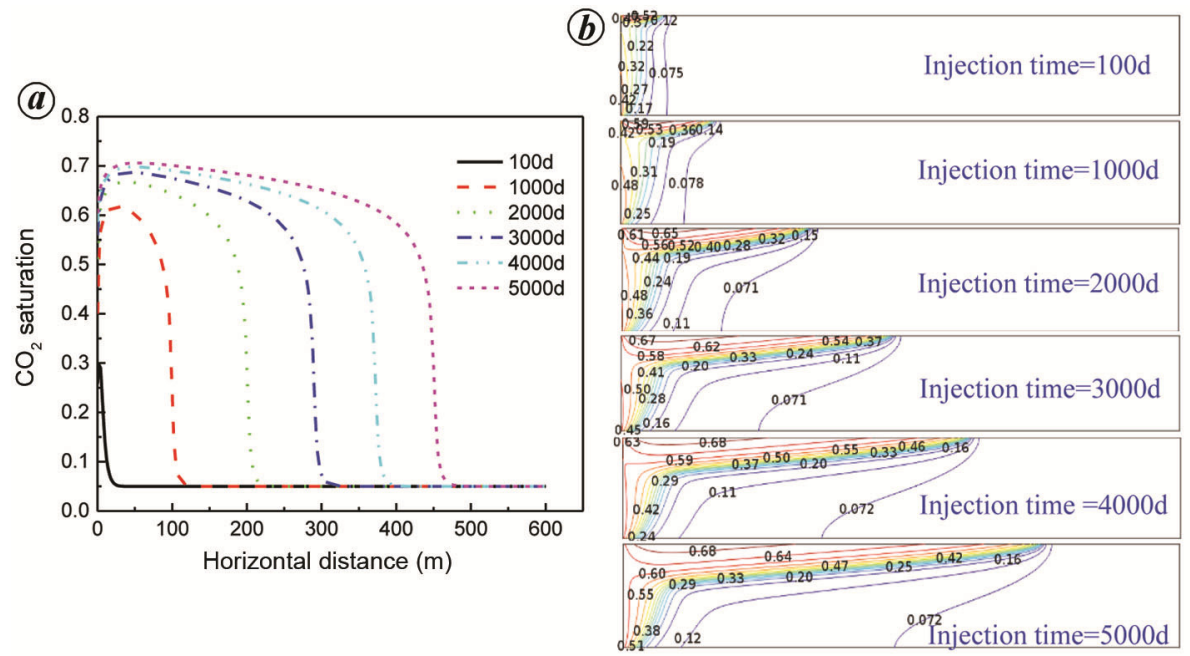

Figure 6. Variation of spatial distribution of $\mathrm{CO}_{2}$ with time in the THM coupled model. a, Distribution of $\mathrm{CO}_{2}$ saturation along the top boundary of the reservoir. $\boldsymbol{b}$, Isoline distribution of $\mathrm{CO}_{2}$ saturation at different times.
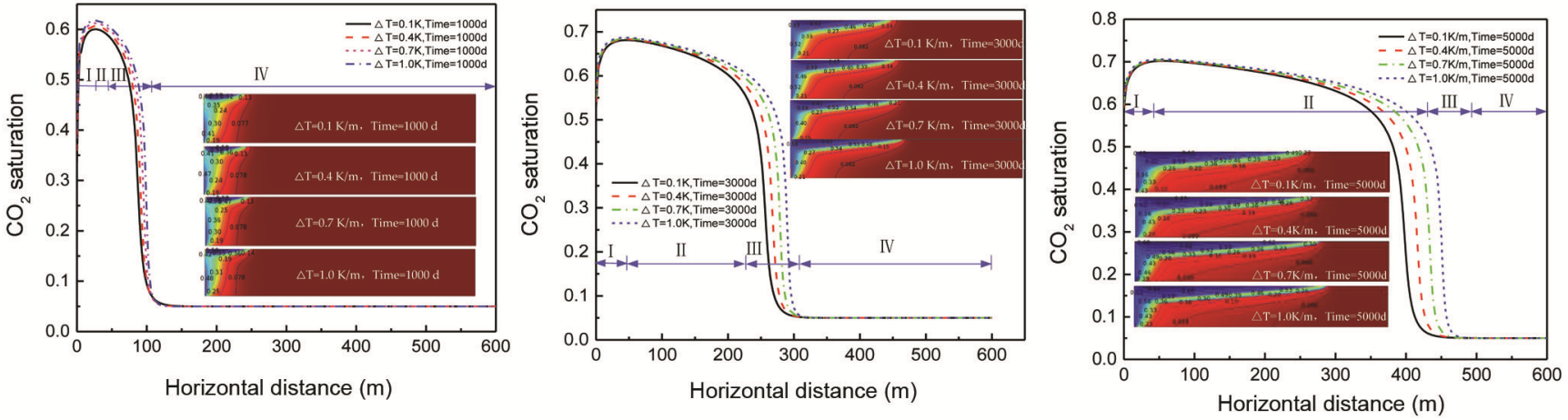

Figure 7. Distribution of $\mathrm{CO}_{2}$ under different geothermal gradients.

Figure $6 b$ indicates that for any spatial point in the reservoir, the saturation of $\mathrm{CO}_{2}$ at this point gradually increases with continuous migration into the reservoir. With regard to variation in the shape of the $\mathrm{CO}_{2}$-brine interface with time, the longer the distance to the borehole, the larger is the front distance of $\mathrm{CO}_{2}$ migration. Also, the $\mathrm{CO}_{2}$-brine interface is correspondingly steeper because viscosity force in the lower part of the reservoir is larger than that in the upper part, and effect of viscosity force is stronger than that of gravity ${ }^{33,35,36}$.

It can also be seen from Figure 7 that the fast decrease region is before the initial saturation region. This is because there is a mixed transition region between the injected well and the reservoir far from the well. The closer the mixed transition region to the well, less is the difference in the temperature and pressure. On the contrary, the farther the mixed transition region to the well, more is difference in the temperature and pressure between the injected $\mathrm{CO}_{2}$ and the saline aquifer. Therefore, the fast decrease region comes before the initial saturation region.
Figure 7 also shows the spatial distribution of $\mathrm{CO}_{2}$ saturation under geothermal gradients of $0.1,0.4,0.7$ and $1.0 \mathrm{k} / \mathrm{m}$. Analysis of saturability distribution curves of $\mathrm{CO}_{2}$ at times of 1000, 3000 and $5000 \mathrm{~d}$ shows that a larger geothermal gradient corresponds to a greater distance of $\mathrm{CO}_{2}$ migration front because with the increase in the geothermal gradient, the difference in dynamic viscosity of supercritical $\mathrm{CO}_{2}$ in the upper and lower parts of the reservoir also increases. The dynamic viscosity of supercritical $\mathrm{CO}_{2}$ in the upper reservoir is relatively small, and resistance of $\mathrm{CO}_{2}$ flow in the upper reservoir is also small. Within the same time frame, the migration velocity as well as distance of the supercritical $\mathrm{CO}_{2}$ migration front in the upper reservoir are larger. This phenomenon is termed the gravity override effect.

Figure 7 also indicates that at the same location, a larger geothermal gradient corresponds to a greater $\mathrm{CO}_{2}$ saturation, because the reservoir temperature and pressure affect the density of $\mathrm{CO}_{2}$ (Figures $1 a$ and $5 a, c$ ). At constant pressure, the density of supercritical $\mathrm{CO}_{2}$ is inversely 
proportional to temperature. Since temperature in the upper reservoir is less than that in the lower reservoir, the density of supercritical $\mathrm{CO}_{2}$ in the upper reservoir is larger than in the lower reservoir. The larger the geothermal gradient, greater is the temperature difference between the upper and lower reservoirs and the difference in $\mathrm{CO}_{2}$ density is correspondingly larger. If the injection rate of $\mathrm{CO}_{2}$ is constant, $\mathrm{CO}_{2}$ density in the upper reservoir is larger than in the lower reservoir. As a result, more $\mathrm{CO}_{2}$ could be stored in the upper reservoir compared to the lower reservoir. Within the same time-frame, the distance of $\mathrm{CO}_{2}$ migration front in the upper reservoir is relatively larger.

In addition to reservoir temperature, the spatial distribution of $\mathrm{CO}_{2}$ is also affected by the following factors: (i) $\mathrm{CO}_{2}$ injected into the lower part of the brine aquifer with high temperature would flow upward along the $\mathrm{CO}_{2}-$ brine interface; (ii) brine in the upper aquifer with lower temperature would flow downwards along the $\mathrm{CO}_{2}$-brine interface; (iii) the temperature of $\mathrm{CO}_{2}$ will decrease because of the Joule-Thomson effect after $\mathrm{CO}_{2}$ enters the reservoir from the borehole, and (iv) the dissolution of $\mathrm{CO}_{2}$ in brine is a heat-release process. All these factors will slightly increase the temperature of supercritical $\mathrm{CO}_{2}$ and affect the distribution ${ }^{7}$.

\section{Conclusion}

The injection pressure of $\mathrm{CO}_{2}$ is highly sensitive to reservoir temperature and pressure, and this sensitivity becomes more significant when the reservoir conditions are close to the critical point. Compared with $\mathrm{CO}_{2}$ injection pressure calculated by the THM coupled model in this study, the injection pressure of $\mathrm{CO}_{2}$ calculated by an uncoupled model based on the ideal gas EoS, and Span and Wagner EoS was relatively low. The THM coupled model was established based on the continuous calculation of physical property parameters of gaseous, liquid and supercritical $\mathrm{CO}_{2}$. Therefore, the THM coupled model can be used to truly reflect the process of multiphase flow and heat flow, and to accurately predict the injection pressure.

Under the THM coupled function, the spatial distribution of $\mathrm{CO}_{2}$ is characterized by the obvious gravity override along the vertical direction. Different $\mathrm{CO}_{2}$ saturability regions occur along its migration direction at the top boundary of the saline aquifer, i.e. fast increase region, slow decrease region, fast decrease region and initial saturation region. The larger the geothermal gradient, greater is the $\mathrm{CO}_{2}$ saturation at the top boundary of the reservoir; the reservoir space needed to sequester $\mathrm{CO}_{2}$ is correspondingly smaller. The reason for $\mathrm{CO}_{2}$ spatial distribution is that the physical property parameters such as density and dynamic viscosity of $\mathrm{CO}_{2}$ are influenced by the reservoir temperature and pressure.
Conflicts of interest: The authors declare no conflict of interest.

1. Nwachukwu, A., Min, B. and Sriniyasan, S., Model selection for $\mathrm{CO}_{2}$ sequestration using surface deformation and injection data. Int. J. Greenhouse Gas Control, 2017, 56, 67-92.

2. Kim, S. and Hosseini, S. A., Study on the ratio of pore-pressure/ stress changes during fluid injection and its implications for $\mathrm{CO}_{2}$ geologic storage. J. Pet. Sci. Eng., 2017, 149, 138-150.

3. Jiang, P., Li, X. and $\mathrm{Xu}, \mathrm{R}$., Thermal modeling of $\mathrm{CO}_{2}$ in the injection well and reservoir at the Ordos CCS demonstration project, China. Int. J. Greenhouse Gas Control, 2014, 23, 135146.

4. Brassard, P., Godbout, S. and Raghavan, V., The production of engineered biochars in a vertical auger pyrolysis reactor for carbon sequestration. Energies, 2017, 10, 288.

5. Yin, S., Dusseault, M. B. and Rothenburg, L., Coupled THMC modeling of $\mathrm{CO}_{2}$ injection by finite element methods. J. Pet. Sci. Eng., 2011, 80, 53-60.

6. Zhan, J. et al., Decomposition analysis of the mechanism behind the spatial and temporal patterns of changes in carbon bio-sequestration in China. Energies, 2012, 5, 386-398.

7. Li, C. and Laloui, L., Coupled multiphase thermo-hydromechanical analysis of supercritical $\mathrm{CO}_{2}$ injection: benchmark for the in Salah surface uplift problem. Int. J. Greenhouse Gas Control, 2016, 51, 394-408.

8. Hou, Z., Gou, Y. and Taron, J., Thermo-hydro-mechanical modeling of carbon dioxide injection for enhanced gas-recovery $\left(\mathrm{CO}_{2}-\right.$ EGR): a benchmarking study for code comparison. Environ. Earth Sci., 2012, 67, 549-561.

9. Li, J., Chen, A. and Yan, Y., Numerical simulation of carbon dioxide migration in a sandstone aquifer considering the fluid-solid coupling. Acta Geotech., 2014, 9, 101-108.

10. Li, Q., Wu, Z. and Bai, Y., Thermo-hydro-mechanical modeling of $\mathrm{CO}_{2}$ sequestration system around fault environment. Pure Appl. Geophys., 2006, 163, 2585-2593.

11. Li, S., Li, X. and Zhang, D., A fully coupled thermo-hydromechanical, three-dimensional model for hydraulic stimulation treatments. J. Nat. Gas Sci. Eng., 2016, 34, 64-84.

12. Fang, Y., Ba, N. N. and Carroll, K., Development of a coupled thermo-hydro-mechanical model in discontinuous media for carbon sequestration. Int. J. Rock Mech. Min. Sci., 2013, 62, 138147.

13. Basirat, F., Fagerlund, F. and Denchik, N., Numerical modelling of $\mathrm{CO}_{2}$ injection at small-scale field experimental site in Maguelone, France. Int. J. Greenhouse Gas Control, 2016, 54, 200-210.

14. Khan, S., Al-Shuhail, A. A. and Khulief, Y. A., Numerical modeling of the geomechanical behavior of Ghawar Arab-D carbonate petroleum reservoir undergoing $\mathrm{CO}_{2}$ injection. Environ. Earth Sci., 2016, 75, 1499.

15. Liu, H., Hou, Z. and Were, P., Numerical investigation of the formation, displacement and caprock integrity in the Ordos Basin (China) during $\mathrm{CO}_{2}$ injection operation. J. Pet. Sci. Eng., 2016, 147, 168-180.

16. Du, Z., Lin, W. and Gu, J., Numerical investigation for heat transfer of supercritical $\mathrm{CO}_{2}$ cooled in a vertical circular tube. Heat Transfer Eng., 2012, 33, 905-911.

17. Joshi, A., Gangadharan, S. and Leonenko, Y., Modeling of pressure evolution during multiple well injection of $\mathrm{CO}_{2}$ in saline aquifers. J. Nat. Gas Sci. Eng., 2016, 36, 1070-1079.

18. Sasaki, K., Fujii, T. and Niibori, Y., Numerical simulation of supercritical $\mathrm{CO}_{2}$ injection into subsurface rock masses. Energy Convers. Manage., 2008, 49, 54-61.

19. Aavatsmark, I., Kometa, B. K. and Gasda, S. E., A generalized cubic equation of state with application to pure $\mathrm{CO}_{2}$ injection in aquifers. Comput. Geosci., 2016, 20, 623-635. 
20. Youssef, Z., Barreau, A. and Mougin, P., Measurements of hydrate dissociation temperature of gas mixtures in the absence of any aqueous phase and prediction with the cubic-plus-association equation of state. J. Chem. Eng. Data, 2010, 55, 2809-2814.

21. Peng, D. Y. and Robinson, D. B., A new two-constant equation of state. Ind. Eng. Chem. Fundam., 1976, 15, 92-94.

22. Wu, X., Wang, Q. and He, Y., Temperature-pressure field coupling calculation model considering phase behavior change in $\mathrm{CO}_{2}$ injection well borehole. J. China Univ. Pet. (Edn. Nat. Sci.), 2009, 1, 73-77.

23. Jossi, J. A., Stiel, L. I. and Thodos, G., The viscosity of pure substances in the dense gaseous and liquid phases. Aiche J., 1962, 1, 59-63.

24. Poling, B. E., Prausnitz, J. M. and O'Connell, J. P., The Properties of Gases and Liquids, McGraw-Hill, New York, USA, 2001, 5th edn, pp. 6.1-6.33.

25. Guo, X., Rong, S. and Yang, J., The viscosity model based on PR equation of state. Acta Pet. Sin., 1999, 3, 64-69.

26. Shi, J., The distribution of temperature and pressure and injection string check of the injection and production wellbore of $\mathrm{CO}_{2}$ flooding. China University of Petroleum-Beijing, Beijing, China, 2009, pp. 12-30.

27. Schnepper C. A. and Stadtherr, M. A., Robust process simulation using interval methods. Comput. Chem. Eng., 1996, 20, 187-199.

28. Wang, L. and Liu, Y., Simulation on characteristics of supercritical fluid flow in porous media imposed temperature profiles. Chem. React. Eng. Technol., 1996, 20, 187-199.

29. Zirrahi, M., Hassanzadeh, H. and Abedi, J., Prediction of $\mathrm{CO}_{2}$ solubility in bitumen using the cubic-plus-association equation of state (CPA-EoS). J. Supercrit. Fluids, 2015, 98, 44-49.

30. Chung, F. T., Jones, R. A. and Nguyen, H. T., Measurements and correlations of the physical properties of $\mathrm{CO}_{2} /$ heavy-crude-oil mixtures. Spe. Reserv. Eng., 1988, 3, 822-828.

31. Kong, X., High Seepage Mechanical, Press of University of Science and Technology of China, Hefei, 2010, pp. 11-79.
32. Li, P., Kong, X. and Lu, D., Mathematical modeling of flow in saturated porous media on account of fluid-structure coupling effect. J. Hydrodyn., 2003, 4, 419-426.

33. Chen, J., Hopmans, J. W. and Grismer, M. E., Parameter estimation of two-fluid capillary pressure-saturation and permeability functions. Adv. Water Resour., 1999, 22, 479-493.

34. Vilarrasa, V., Silva, O. and Carrera, J., Liquid $\mathrm{CO}_{2}$ injection for geological storage in deep saline aquifers. Int. J. Greenhouse Gas Control, 2013, 14, 84-96.

35. Vilarrasa, V., Koyama, T. and Neretnieks, I., Shear-induced flow channels in a single rock fracture and their effect on solute transport. Transp. Porous Media, 2011, 87, 503-523.

36. Lu, C., Lee, S. Y., and Han, W. S., Comments on 'abrupt-interface solution for carbon dioxide injection into porous media' by $\mathrm{M}$. Dentz and D. Tartakovsky. Transp. Porous Media, 2009, 79, 2937.

ACKNOWLEDGEMENTS. This work was supported by the Transformation of Scientific and Technological Achievements Programs (TSTAP) of Higher Education Institutions in Shanxi (No. 2020CG050), the Special Project of 2019 Plan for the Introduction of High-Level Scientific and Technological Talents in Development Zone of Lvliang City (development of automatic disassembly platform for hydraulic support pin shaft) (No. 2019L0002) and the Science and Technology Project of Lvliang City in 2019 (Pressure relief and permeability improvement technology by integrated hydraulic flushing and cutting for low permeability coal seam containing methane) (No. 2019L0008).

Received 30 May 2019; revised accepted 15 June 2020

doi: $10.18520 / \mathrm{cs} / \mathrm{v} 119 / \mathrm{i} 6 / 973-983$ 